\section{Commentary: Tinker, tailor, surgeon, scholar-effective surgical management of glotto-subglottic stenosis}

\author{
Ashok Muniappan, MD
}

\section{Disease does not tidily respect our anatomical and jurisdictional boundaries.}

—Hermes Grillo, STS Presidential Address, 1988

In their article in this issue of the Journal, Schweiger and colleagues graciously refer to the pioneering work of Aurel Rethi, a Hungarian otolaryngologist active in the first half of the 20th century, in the introduction to an update on their group's experience with a single-stage operation for glotto-subglottic stenosis (GSGS). ${ }^{1}$ Their group has mixed and matched the "greatest hits" of tracheal surgery, incorporating techniques developed by otolaryngologists and thoracic surgeons alike, to effectively treat the challenging problem of an airway stricture involving the subglottic larynx and extending through the glottis. Their approach, which they term "single-stage laryngotracheal resection" (SSLTR), combines a posterior laryngeal split, laryngeal augmentation with a cartilage graft, circumferential resection of subglottic scar, and resurfacing of the posterior cricoid with a membranous tracheal flap to correct GSGS. This last step obviates the need for a laryngeal stent, which the authors are correct to surmise could contribute to ischemia and granulation, complicating operations at other centers. They report longer-term follow-up in a cohort of 15 patients and achievement of universally successful correction of breathing difficulties without recurrences or major anastomotic

\footnotetext{
From the Division of Thoracic Surgery, Massachusetts General Hospital, Boston, Mass.

Disclosures: The author reported no conflicts of interest.

The Journal policy requires editors and reviewers to disclose conflicts of interest and to decline handling or reviewing manuscripts for which they may have a conflict of interest. The editors and reviewers of this article have no conflicts of interest.

Received for publication Nov 27, 2020; revisions received Nov 27, 2020; accepted for publication Nov 30, 2020; available ahead of print Dec 7, 2020.

Address for reprints: Ashok Muniappan, MD, Division of Thoracic Surgery, Massachusetts General Hospital, WG Austen Building 7, 55 Fruit St, Boston, MA 02114 (E-mail: amuniappan@mgh.harvard.edu).

J Thorac Cardiovasc Surg 2022;163:323-4

$0022-5223 / \$ 36.00$

Copyright (c) 2020 by The American Association for Thoracic Surgery

https://doi.org/10.1016/j.jtcvs.2020.11.148
}

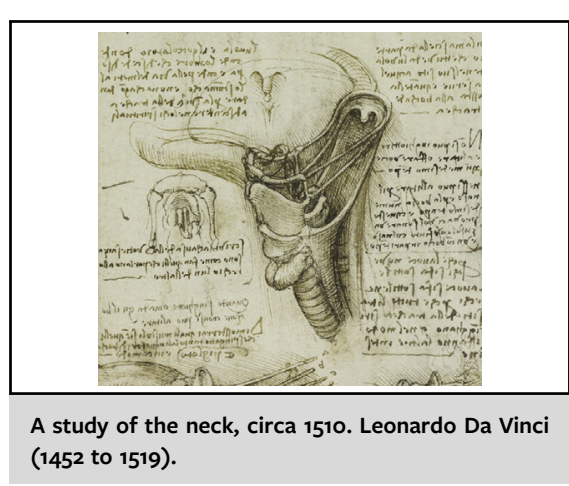

CENTRAL MESSAGE

An effective operative approach to glotto-subglottic stenosis requires a posterior cricoid split, cartilage interposition, and mucosal resurfacing. Although breathing is improved, the voice may degrade.

complications. The excellent outcomes are likely due to careful patient selection, meticulous operative technique, and considerable multidisciplinary expertise at their center.

A strength of this report is the exhaustive functional assessment that the patients underwent after SSLTR. The authors observed markedly significant improvements in measures of expiratory airflow in the entire cohort. Fortunately, no patient had difficulty with aspiration or deglutition after formal assessment by speech and swallow therapists. Finally, and perhaps not surprisingly, most patients had an objectively deeper (ie, lower-frequency) voice postoperatively. Removing the anterior cricoid results in a characteristic deepening of the voice; a posterior cricoid split and extension of the operation into the interarytenoid mucosa and anterior commissure can exacerbate this phenomenon. Patients likely were not overly bothered by any degradation in voice quality, given the marked and durable improvement in breathing and the avoidance of a tracheal appliance.

Future observational studies in tracheal surgery should emulate this report in the careful tallying of patient-reported outcomes and use formal objective measures to document the effects of surgery on breathing, voice, and swallowing.

Although thoracic surgeons are most familiar with the maximally invasive approach to subglottic stenosis (SGS), which entails circumferential segmental resection and reconstruction, they may be less familiar with the strides otolaryngologists have made with endoscopic techniques. ${ }^{2}$ Laser 
resection of SGS with buccal mucosal grafts, termed the Maddern procedure by one of its proponents, is an example of advanced endoscopic management. ${ }^{3}$ A report describing patient selection and early outcomes with this specific technique is anticipated. In the meantime, the North American Airway Collaborative group recently published a multiinstitution cohort study suggesting that endoscopic resection is more durable than dilation alone, with the advantage of less morbidity and effect on the voice compared with cricotracheal resection. ${ }^{4}$ Otolaryngologists have performed endoscopic posterior cricoid splits; it is natural to wonder whether they will attempt a completely endoscopic approach to GSGS. ${ }^{5}$ Careful, objective, and fair comparisons of patients undergoing endoscopic and open surgery for SGS will guide patients and surgeons alike.

Airway surgery continues to evolve. Thoracic surgeons and their many partners in otolaryngology, anesthesiology, and speech therapy continue to refine techniques and collaborate in innovative ways. Their scholarship articulates the artistry of tracheal surgery.

\section{References}

1. Schweiger T, Roesner I, Rodrigues IFS, Everman M, Frick AE, Denk-Linnert D-M, et al. Functional outcome after single-stage laryngotracheal reconstruction with rib cartilage grafting. J Thorac Cardiovasc Surg. 2022;163:313-22.e3.

2. Mayo Clinic. Microdirect laryngoscopy with $\mathrm{CO}_{2}$ laser wedge excisions for subglottic stenosis; 2020. Available at: https://youtu.be/aa_NfiL9oNk. Accessed November 25, 2020.

3. Daniero JJ, Ekbom DC, Gelbard A, Akst LM, Hillel AT. Inaugural symposium on advanced surgical techniques in adult airway reconstruction: proceedings of the North American Airway Collaborative (NoAAC). JAMA Otolaryngol Head Neck Surg. 2017;143:609-13.

4. Gelbard A, Anderson C, Berry LD, Amin MR, Benninger MS, Blumin JH, et al. Comparative treatment outcomes for patients with idiopathic subglottic stenosis. JAMA Otolaryngol Head Neck Surg. 2020;146:20-9.

5. Yawn RJ, Daniero JJ, Gelbard A, Wootten CT. Novel application of the Sonopet for endoscopic posterior split and cartilage graft laryngoplasty. Laryngoscope. 2016;126:941-4.
See Article page 313

\section{Commentary: Size matters, at least when it pertains to the trachea and ventilation}

\author{
Richard S. Lazzaro, MD, Byron Patton, MD, and \\ Matthew L. Inra, MD
}

Over the past year, the novel Coronavirus Disease 2019 pandemic has hospitalized people worldwide because of the severe acute respiratory syndrome and interstitial pneumonia that it causes. Intensive care unit (ICU) admissions were found to be as high as $32 \%$ in one meta-analysis. ${ }^{1}$ The mortality rate of ICU admissions was not $100 \%$; anecdotally, many patients who did leave the ICU were

From the Department of Cardiothoracic Surgery, Lenox Hill Hospital, New York, NY. Disclosures: The authors reported no conflicts of interest.

The Journal policy requires editors and reviewers to disclose conflicts of interest and to decline handling or reviewing manuscripts for which they may have a conflict of interest. The editors and reviewers of this article have no conflicts of interest.

Received for publication Nov 20, 2020; revisions received Nov 20, 2020; accepted for publication Nov 23, 2020; available ahead of print Dec 3, 2020.

Address for reprints: Richard S. Lazzaro, MD, Department of Cardiothoracic Surgery, Lenox Hill Hospital, 130 E 77th St, New York, NY 10075 (E-mail: rlazzaro@ northwelli.edu).

J Thorac Cardiovasc Surg 2022;163:324-5

$0022-5223 / \$ 36.00$

Copyright (c) 2020 by The American Association for Thoracic Surgery

https://doi.org/10.1016/j.jtcvs.2020.11.127
Check for updates

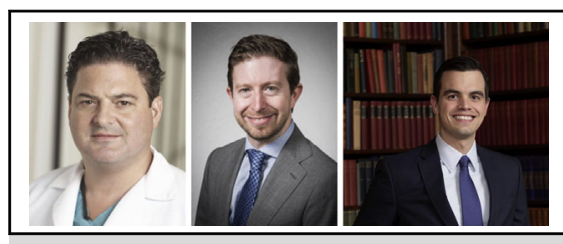

Richard S. Lazzaro, MD, FACS, Byron Patton, MD, and Matthew L. Inra, MD

CENTRAL MESSAGE

Sound patient selection and surgical technique combined with grafting as an adjunct to reconstruction for tracheal stenosis are powerful tools for today's surgeons, and tomorrow's patients will benefit starting today.

intubated for prolonged periods of time or had tracheostomies placed. Benign tracheal stenosis has long been described as a complication of prolonged intubation or tracheostomy, and it is no different in the patients who were intubated for extended periods because of Coronavirus Disease 2019. 